\title{
Los Debates en Torno al Concepto de Ciudadanía en Sociedades EN TRANSFORMACIÓN ${ }^{1}$
}

\author{
Silvia Levín ${ }^{2}$
}

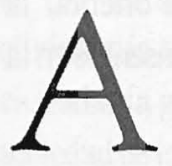

fines del siglo XX y comienzos del siglo XXI la ciudadanía enfrenta un nuevo escenario de dimensiones y magnitud inmensurables. Los procesos de globalización o también denominados de mundialización, que trascienden los grupos, las clases sociales y aún las naciones, anuncian lo que algunos autores han denominado el advenimiento de la sociedad global ${ }^{3}$. Estos procesos, que reorientan la organización de las sociedades actuales, colocan a la categoría ciudadanía en el desafío de redefinir aquellos supuestos estructurales centrales que le han otorgado sentido y contenido durante siglos: universalidad, libertad e igualdad.

Los criterios que permitieron la definición de un modelo cívico inclusivo son cuestionados por nuevos actores y demandas diferenciadas y, en consecuencia, se le exige a la democracia y a la ciudadanía la capacidad de tolerar el conflicto y encauzarlo sobre la base de nuevos principios de organización o bien de una nueva relación entre los componentes constitutivos de la ciudadanía. Se trata en definitiva de discutir qué formato deberá adoptar la ciudadanía en el espacio político común para garantizar la convivencia democráticapero en un escenario global, donde los supuestos que definieron la inclusividad han perdido consenso y el disenso se disputa en antagonismos: universalidad/ particularidad, libertad/sometimiento, igualdad/diferencia.

Necesita entonces reafirmar hoy su condición de categoría histórica, demostrar su capacidad y dinamicidad para captar las nuevas realidades que enfrenta la sociedad y a la vez mantener sus roles tradicionales, reconocidos por la mayor parte de la literatura: contribuir a la cohesión social y a la convivencia democrática.

1 El presente trabajo fue elaborado sobre la base de los avances teóricos producidos en la Tesis Docroral que estamos desarrollando: "Los alcances de los derechos de ciudadanía de la mujer em Argentina entre 1990 y 2003. El reconocimiento de los derechos sexuales y reproductivos". Doctorado em Ciencias Sociales, cohorte 2002/2004, Flacso, Buenos Aires.

2 Profesora Titular de Política Social de la Facultad de Ciencia Política y Relaciones Internacionales de la Universidad Nacional de Rosario, Argentina.

3 ORTIZ, R. Mundializacao e cultura. Editora brasiliense, Sao Paulo, Brasil, 2000. 
En este marco nos proponemos revisar las distintas corrientes de pensamiento que han contribuido a definir la ciudadanía y, al mismo tiempo, reflexionar en el escenario de las transformaciones actuales sobre uno de los problemas inherentes a su naturaleza: la tensión entre universalismo y particularismo. El universalismo es hoy interpelado en el escenario global y es uno de los supuestos que origina la discusión acerca de la necesidad de redefinir la concepción y el contenido actual de la ciudadanía. Se trata de que la ciudadanía redefinael "nosotros" en diálogo con los "otros". Nuestra intención es recuperar el hilo conductor del debate entorno a esta problemática a partir de la revisión crítica de algunas líneas de pensamiento contemporáneas. El objetivo final es mostrar las posibilidades potenciales que presenta como categoría conceptual para orientar la reorganización de las relaciones sociales sobre la base de la renovación de consensos en la comunidad política del mundo global.

\section{Distintas Concepciones de Ciudadanía: Enfoques y Perspectivas Analíticas}

El tema de la ciudadanía viene ocupando un lugar privilegiado en las investigaciones y debates de los estudiosos de las ciencias sociales en estos últimos quince años. Como señalan algunos autores ${ }^{4}$ el concepto de ciudadanía ha experimentado una "verdadera explosión" en los años noventa como resultado de una serie de hechos y circunstancias que le asignan un interés particular.

Dahrendorf ${ }^{5}$ señala que el resurgimiento del interés por los derechos de ciudadanía, constituyéndose en un concepto de moda, obedece a un signo propio de los tiempos. Así, advierte, "la gente percibe que hay en ella algo que define las necesidades del futuro -y en esto tienen razón-, pero se dedica al moldear el término de acuerdo con sus propias preferencias". Así como los años ochenta se caracterizaron por el crecimiento económico, no sólo en Europa sino practicamente en todo el mundo, por el afianzamiento y expansión de lo que el denomina "las provisiones", en los noventa se perciben signos de cambio: el énfasis puesto en los derechos.

La sistematización de los distintos enfoques implícitos en los conceptos de ciudadanía moderna formulados en la literatura, partiendo de autores clásicos como

\footnotetext{
4 Kymlicka, W. y Norman WAYNe, "El retorno del ciudadano. Una revisión de la producción reciente en teoría de la ciudadanía" en Agora Cuaderno de Estudios Políticos, №7, invierno de 1997, Año 3, Buenos Aires.

5 Dahrendorf, Ralf, "La naturaleza cambiante de la ciudadanía", en La Politica. Revista de estudios sobre el Estado y la sociedad, Ciudadanía. El debate contemporáneo, № 3, Paidós, octubre de 1997, Bs.As. pág. 139.
} 
Marshall con su esbozo de una "teoría de la ciudadanía" y llegando a la actualidad, delimita un interesante campo de trabajo en tanto permite mostrar la dinamicidad que presenta el contenido de la ciudadanía y reafirmar su condición de categoría histórica.

\section{Concepciones legalistas: Ciudadanía y Derechos}

Ubicamos aquí a aquellas corrientes de pensamiento que definen a la ciudadanía en términos de posesión de derechos. La exposición más trascendente de esta perspectiva fue la del sociólogo inglés Thomas H.Marshall quien elabora una teoría de la ciudadanía en 1949 en su obra "Ciudadanía, Clase Social y Status". Este autor considera que la ciudadanía moderna supone un status social que atribuye derechos y deberes. La ciudadanía garantiza que cada individuo sea tratado como un miembro pleno en una sociedad de iguales. La pertenencia a una comunidad está asegurada, entonces, a partir del otorgamiento de un número creciente de derechos de ciudadanía. En estos términos, el concepto de ciudadanía reconoce una relación directa entre el Estado y los ciudadanos. El Estado a través de la legislación otorga formalmente los derechos a los ciudadanos y estos a su vez ejercen esos derechos pero también deben cumplir obligaciones frente al Estado, por ejemplo: pagar impuestos, votar, asistir a la escuela primaria, etc.

Desde esta perspectiva, la pertenencia a una comunidad queda asegurada a partir del otorgamiento creciente de derechos de ciudadanía a los individuos. Es justamente el reconocimiento de derechos lo que afianza la relación entre individuos y Estado. De allí la preocupación de Marshall por identificar los distintos tipos de derechos que integran la ciudadanía y que reconocen momentos históricos diferentes en su aparición en Inglaterra.

La hipótesis central de Marshall es que hay una igualdad humana básica 0 elemental asociada al principio de pertenencia a una comunidad -status legal de ciudadanía-que no se contradice con las desigualdades de clase, esto es, con las desigualdades económicas y sociales. Es decir que la desigualdad del sistema de clases sociales puede ser aceptable mientras la igualdad de ciudadanía sea reconocida. En su concepción de ciudadanía, derechos e instituciones constituyen dos componentes centrales. Distingue en su análisis tres esferas de derechos -civiles, políticos y sociales- y las instituciones comprometidas con la efectiva realización de los mismos.

La dinámica de evolución y desarrollo de cada una de esas esferas llevó a configurar distintos tipos de ciudadanía: la civil, la política y la social. Marshall señaló que lo que

6 Marshall, T.H. Cidadanía, classe social e status, Zahar Editores, Río de Janeiro, 1965. 
une a esos tres tipos de ciudadanía es el principio de libertad y, lo que las distingue es su tensión respecto a la igualdad. Tanto el capitalismo como la lógica del mercado funcionan sobre la base de la desigualdad, en consecuencia, se interrogaba ¿cómo puede estabilizarse o extenderse la ciudadanía en un sistema en cuya base subsiste la tensión entre igualdad y libertad? El problema principal se presentaba con los derechos sociales. El desarrollo de la ciudadanía social encuentra su límite en el sistema de estratificación social. No se puede aspirar a la igualdad en los ingresos, advertía Marshall, pero sí puede aspirarse a un mejoramiento de la calidad de vida de los sujetos de una comunidad.

Si bien el reconocimiento de la ciudadanía social no puede por sí solo modificar la estructura de la distribución de la riqueza e ingresos, que resulta de la asignación de recursos producidos por el mercado, sí puede alterar su forma de funcionamiento garantizando un mínimo de bienestar social para todas las personas independientemente de sus fuentes de recursos. Esta concepción de ciudadanía requiere, en su máxima expresión, de un Estado de bienestar liberal-democrático. Este modelo de Estado es capaz de garantizar a todos los ciudadanos el goce de los derechos civiles, políticos y sociales integrándolo plenamente a la vida en común.

\section{Ciudadanía e InCluUsividad}

Reinhard Bendix ${ }^{7}$ consideraba que si bien la ciudadanía implica reconocimiento de derechos, la cuestión central reside en el grado de inclusividad con que se la define, es decir con el contenido que se le asignan a esos derechos.

En el Estado Nacional cada ciudadano guarda una relación directa con la autoridad soberana del país -es decir con el Estado- contrariamente a lo que ocurría con el sistema político medieval donde únicamente los grandes del reino mantenían esa relación directa. Por tanto, advierte Bendix, un elemento clave de la formación nacional es la codificación de los derechos y de las obligaciones de todas las personas adultas consideradas como ciudadanos. El Estado es quien otorga la ciudadanía y guarda una relación directa con el ciudadano en tanto es titular de derechos y obligaciones. De allí surge la importancia de codificar los derechos y obligaciones - a través de los cuerpos de leyes o códigos- de todas las personas clasificadas como ciudadanos.

La definición de ciudadanía de este autor nos permite identificar dos elementos para el análisis: por un lado, su referencia al contenido de los derechos y, por otro, la posibilidad concreta de ejercerlos. Parte del supuesto que la igualdad jurídica, o la igualdad

7 Bendix, Reinhard, Estado Nacional y ciudadanía, Ed. Amorrortu, Bs.As. 1974, pág.78. 
ante la ley constituye la base de los derechos de ciudadanía. No obstante advierte, que esta igualdad legal va acompañada por la desigualdad económica y social propia del capitalismo y de la existencia de clases sociales. Si bien se le reconoce a todo individuo el derecho a defender sus libertades civiles básicas en un plano de igualdad, se trata de un derecho formal dado que se le garantizan facultades legales sin ayudarlo en absoluto a hacer uso de tales facultades. En este sentido, dice Bendix, la igualdad de la ciudadanía y las desigualdades de clase se desarrollan juntas.

Podemos señalar aquí una diferencia entre Bendix y Marshall en el modo de articular el problema de la igualdad ante la ley con las desigualdades sociales y económicas que se encuentran en la base de la estructura de clases propias del capitalismo. Así, mientras Marshall advertía que es posible que convivan ambas mientras la igualdad de la ciudadanía sea reconocida -igualdad de derechos en términos legales-, Bendix considera que las desigualdades de clase no afectan el reconocimiento formal de los derechos pero sí limitan o dificultan su ejercicio real. Los derechos civiles son otorgados a quienes poseen medios para protegerse a sí mismos, dejando librado a su suerte a quienes no reúnen esas condiciones.

El derecho social fundamental, para este autor al igual que Marshall, es el derecho a la educación elemental. Este derecho se presenta como un prerrequisito sin el cual ninguno de los restantes derechos reconocidos por ley pueden ejercerse. Para Bendix, proporcionar a grandes núcleos de población privados de educación el acceso a ese beneficio implica un acto de liberación, les permite potenciar su capacidad de acceso y ejercicio a otros derechos.

Al examinar los derechos sociales en particular se advierte que el principio de la igualdad ante el Estado nacional implica no sólo derechos sino también deberes, obligaciones. Cada individuo está obligado a participar en los servicios que el Estado le proporciona. La ciudadanía ofrece, entonces, dos aspectos o dos dimensiones constitutivas: derechos y obligaciones.

En definitiva, la preocupación de Bendix en torno al concepto de ciudadanía gira en relación al problema de la inclusividad que constituye el nudo de su argumentación. Recurre a la historia para tratar de explicar, a partir de la comparación de la estructura medieval con la moderna, cómo se produjo la extensión de la ciudadanía a las clases bajas de Europa Occidental. La articulación necesaria que debe existir entre el reconocimiento formal de los derechos y su efectivo ejercicio remite su análisis al problema de la igualdad. Este análisis evidencia las tendencias simultáneas hacia la igualdad y hacia la creación de una autoridad gubernamental de alcances nacionales. La constitución del Estado nacional moderno es la fuente originaria de los derechos de ciudadanía, y estos 
derechos contienen un signo de igualdad nacional. La vida política se ha ampliado y las clases bajas tienen la oportunidad de participar en forma activa.

Sostieneel autor que el derecho y la obligación de recibir una educación elemental puede considerarse otra manera de igualar a los ciudadanos en lo que atañe a su capacidad para valerse de los derechos que les correspondan. Si bien la educación elemental no proporciona más que una capacidad mínima en este aspecto, es tal vez la materialización mas aproximada y universal de la ciudadanía nacional.

En esta línea de pensamiento podemos ubicar también a Eduardo Bustelo y a Alberto Minujin 8 quienes sostienen que si bien la ciudadanía otorga centralidad a los derechos, debería apuntar a modelos mas inclusivos de organización social. Esta afirmación distingue dos elementos en el concepto de ciudadanía: por un lado, el reconocimiento y ejercicio de derechos y, por otro, su capacidad de garantizar la integración social. Este segundo componente se refiere a que el contenido de la ciudadanía debe apuntar a consolidar el reconocimiento y ejercicio de los derechos básicos necesarios para garantizar una convivencia digna en sociedad. La idea de inclusividad en el concepto de ciudadanía en los autores trabajados nos remite entonces al principio de igualdad en los derechos básicos elementales que permiten sostener la convivencia social.

\section{CONCEPCIONES ACTIVAS DE CIUDADANÍA}

Los enfoques conceptuales analizados se ubican en una perspectiva "pasiva" de ciudadanía al poner énfasis, por un lado, en el Estado como actor fundamental en la construcción de ciudadanía, y por otro, en el reconocimiento y acceso a los derechos. Frente a estas posiciones, se ubican las que promueven una ciudadanía "activa" al considerar que no sólo el Estado debe intervenir en ese proceso sino también la sociedad, y por otra parte, que el status de ciudadano no se agota con el acceso a los derechos.

En esta línea de pensamiento se ubica Hannah Arendt? quien considera a la ciudadanía como el espacio de construcción de lo público. En este espacio público cobra centralidad la noción de la política basada en la idea de ciudadanía republicana, esto es, en el valor e importancia del compromiso cívico y de la deliberación colectiva en todos los temas que afectan a la comunidad política. Esta dimensión activa de la ciudadanía pone el acento en las responsabilidades que los sujetos tienen con la comunidad política

8 Bustelo, Eduardo y Minujin, Alberto "La política social esquiva" en Revista de Ciencias Sociales No\%, Universidad Nacional de Quilmes, Buenos Aires 1997, pág.9.

9 Hannah ARendt, La condición bumana, Piados, Barcelona, 1993 pág.75. 
a la que pertenecen y exige no sólo un discurso sino también un accionar comprometido con el interés general y el bien común.

La posibilidad de ostentar la titularidad de los derechos, según esta autora, surge de la pertenencia a la comunidad política, y esa pertenencia está vinculada a la voluntad de actuar en la esfera pública y no a la mera adscripción a un colectivo ${ }^{10}$. En definitiva, el ser reconocido por los pares como ciudadanos significa que se tiene "derecho a tener derechos" como principio político básico.

Los espacios públicos cobran existencia en tanto los ciudadanos interactúen a través del discurso y la acción, confiriéndole poder a esa acción. Estos recursos permiten construir sus identidades y deliberar colectivamente acerca de los temas de interés común. En este sentido, la esfera pública es aquella dentro de la cual la actividad de la ciudadanía puede expandirse. La práctica de la ciudadanía adquiere sentido y valor porque capacita a cada ciudadano para ejercer sus poderes de acción, desarrollar sus capacidades de juicio y a lograr, mediante el consenso, algunas medidas de eficacia política. La ciudadanía, entonces, no sólo se expresa en el pleno ejercicio de los derechos, sino que se amplía a prácticas de participación en la gestión y administración que nos conectan con una idea más activa de la ciudadanía social ${ }^{11}$.

En esta visión cobra centralidad el desarrollo de espacios públicos, diferentes del Estado, como expresión de autonomía y vitalidad de la sociedad civil. Por ello, la ciudadanía activa exige ser sujeto de derechos y ser sujeto de la construcción pública común, es decir constituirse en actores en la creación de espacios, intereses y discursos públicos con sentido de identidad y pertenencia a una determinada comunidad política. Esa comunidad política debe establecerse sobre relaciones de interdependencia, responsabilidad, solidaridad y lealtad entre sus miembros.

Habermas ${ }^{12}$ sostiene que hoy la ciudadanía no sólo hace referencia a la pertenencia a un Estado como organización, sino también al status que se define por los derechos y deberes de los ciudadanos y al contenido que se les asigna a ellos. Ese status de ciudadano fija en particular los derechos democráticos a los que puede apelar el individuo para introducir cambios en su posición jurídica, de allí su rol activo. Esta concepción actual de ciudadanía es el resultado de un proceso evolutivo que reconoce en sus inicios un

10 Sánchez, Cristina "Paria o ciudadana del mundo" en Manuel Cruz y Fina Birulés (Comps), En torno a Hannah Arendt, Centro de Estudios Constitucionales, Madrid 1994, pág.23.

1 RABOTNIKOF, NORA "Lo público y sus problemas: notas para una reconsideración" en Revista Internacional de Filosofía Politica, $N^{0} 2$, Uned-Unam, Madrid, 1993, pág. 88.

12 HABERMAS, JÜrgen "Ciudadanía e identidad nacional. Consideraciones sobre el futuro europeo" en Revista Debats №39, Marzo de 1992, Valencia, pág.11. 
componente muy fuerte vinculado a la nacionalidad y a la identidad. Recientemente ha experimentado una ampliación al considerarse el status de ciudadano vinculado a la esfera de los derechos civiles.

En la filosofía del derecho existen dos interpretaciones contrarias de esta ciudadanía activa. En la concepción liberal - inspirada en Loocke -, predomina una comprensión individualista instrumental acerca del papel del ciudadano. Se entiende al ciudadano como miembro de una organización quefundauna determinada posición jurídica. Paralatradición republicana prevalece una concepción comunitaristaética-siguiendo aAristóteles-. El individuo pertenece a una comunidad ético-cultural que se determina a sí misma.

Lacorriente liberal concibeal individuo como externo al Estado. El ciudadano contribuye con el Estado a través de los impuestos, participando con el voto y recibe como contrapartida servicios. Desdeestavisión, el ciudadano no sedistingue de las personas privadas que hacen valer sus intereses pre-políticos frente al Estado. La corriente republicana, por el contrario, visualiza a los ciudadanos como integrantes de la comunidad políica, como partes de un todo de manera que sólo pueden formar su identidad personal y social a partirde tradiciones comunes y de instituciones políticas reconocidas. La ciudadanía se actualiza en la praxis de la autodeterminación colectiva. La posición jurídica de ciudadano se constituye mediante una red de relaciones igualitarias de reconocimiento recíproco.

En síntesis, la ciudadanía democrática no debe quedar limitada a la identidad nacional de un pueblo, pero sin embargo, por encima de la pluralidad de formas de vida culturales diversas, exige la socialización de todos los ciudadanos en una cultura política común. La ciudadanía actual requiere de ciudadanos que participen activamente en la construcción y ampliación de la esfera de derechos.

Dahrendorf ${ }^{13}$ sostiene que la ciudadanía constituye un rol social real, provee titularidades (derechos) y obligaciones asociadas a la capacidad de ser miembro de una comunidad y de manera especial, a la nacionalidad. Señala el autor que el principal cambio que se ha dado en los dos últimos siglos en torno a la extensión de la ciudadanía es en relación a nuevas dimensiones de posicionamiento social. Es decir, las nuevas demandas sociales vinculadas al reconocimiento de identidades, religión, sexos, roles, etnias se constituyen en nuevos derechos que a medida que se van institucionalizando definen un nuevo perfil de ciudadanía. Las nuevas demandas de los ciudadanos constituyen en sí mismas una fuente de ampliación de la ciudadanía en términos de contenido, otorgando a los individuos el rol de actores junto al Estado.

13 DahrendoRf, RaLf, El conflicto social moderno. Ensayo sobre la política de la libertad, Mondadori, Grijalbo S.A. Barcelona, 1990, pág. 48. 
Esta posición acerca de la ciudadanía es compartida también por Donatti ${ }^{14}$ quien sostiene que la ciudadanía es en sí misma una relación social, se es ciudadano en relación al sistema político de referencia. Es la relación con el sistema la que funda la identidad de ciudadano y en función de ello se pueden exigir derechos. En función de la relación reclamo derechos o valores. Ahorabien, esa relación entre sujetoy sistema constituye unapertenenciadel sujeto que nunca se pierde, que existe y siempre está presente desde que el sujeto nace. La ciudadanía, según este autor, necesita hoy ser redefinida: debe tornarse menos estatalistay ser mas societaria. Esto implica una desestatización de la ciudadanía sin caer en el puro mercado, sino comprometiendo a los sujetos a una mayor participación en el proceso de construcción de sus derechos de ciudadanía.

\section{Concepciones Críticas de la Ciudadanía Como Categoría de AnÁlisis}

Las posiciones que le restan entidad a la ciudadanía como categoría analítica consideran que no permite dar cuenta de la realidad del sistema capitalista, sino por el contrario, como supuesto teórico oculta su complejidad y reproduce sus condiciones de explotación.

En esta línea de pensamiento se ubica Sonia Fleury, quien en su libro Estado sin ciudadanos, desarrolla minuciosamente sus argumentaciones en torno al concepto de ciudadanía ${ }^{15}$. Entiende a la ciudadanía como una relación que se establece entre los individuos igualados a nivel formal y del Estado, a través de la participación en el ejercicio de lo político y en el atributo de un conjunto de derechos positivos frente a ese Estado. Considera que la ciudadanía oculta las relaciones de desigualdad propias de la existencia de clases sociales con la finalidad de garantizar y reproducir las condiciones de dominación social. El capitalismo, afirma, tiene necesidad de crear al ciudadano en tanto se equipararía, en términos jurídicos y políticos, al trabajador libre capaz de vender su fuerza de trabajo. En consecuencia, la relación de ciudadanía consolida las desigualdades de clase, situando a la igualdad en el plano estrictamente formal que impide modificar las diferencias de clase.

is DonATTI, PIERPAOLo "Una nueva aproximación a los derechos de ciudadanía", traducción Cristina Díaz, septiembre 1994.

15 FLeURY, Sonia, Estado sin ciudadanos, Lugar Editorial, Buenos Aires, 1997, pág. 53. Su producción posterior da cuenta de un cambio en su concepción de ciudadanía, véase por ejemplo FLEURY, SONIA, "Exclusao e Ciudadania. Teoría Da Política Social na América Latina" en Socialis. Revista Lationamericana de Política Social, Volumen 6, Homo Sapiens Ediciones, Rosario, Argentina, 2002, pág. 33/50. 
No obstante ello, considera que si bien por un lado la ciudadanía, en términos de relación individual de derechos entre el ciudadano y el Estado, significó la negación de la existencia de clases sociales por otro lado, su reconocimiento fue imprescindible para la constitución, organización y lucha de las clases dominadas. Ante la ausencia de un principio de justicia, advierte, las teorías que debaten el problema de la ciudadanía limitan su análisis a la noción de derechos sociales como un conjunto de servicios que deben ser prestados a la población para mejorar su calidad de vida, o bien a aspectos vinculados a su formalización jurídico-institucional.

En ambos casos, la expansión de la ciudadanía surgiría como un subproducto del desarrollo económico y de la democracia política, abstrayendo sus relaciones de la estructura de poder y de las relaciones de producción. Desde esta perspectiva, resulta incapaz de explicar las diferenciaciones entre las distintas trayectorias de institucionalización de las demandas sociales en modelos social-demócratas o en países que se alejen de ese modelo como por ejemplo América Latina.

Consideramos que la argumentación que sustenta a estas posturas que le restan entidad a la ciudadanía como categoría teórica no resultan convincentes en tanto, como surge de las reflexiones y análisis presentados en los distintos enfoques, ninguno de ellos desconoce la desigualdad subyacente en el sistema capitalista. Por el contrario, el tema de la igualdad y su tensión con la libertad constituyó una preocupación constante en las distintas líneas de pensamiento en torno a la ciudadanía. Desde Marshall hasta las posturas más actuales hacen explícita su inquietud por la extensión de derechos, la igualdad, los mayores niveles de inclusión social y de participación, y exigen por tanto que estos componentes estén presentes en toda construcción conceptual de ciudadanía.

\section{El Nuevo Mapa del Mundo: Implicancias en la Ciudadanía}

La globalización, o también denominada mundialización ${ }^{16}$, constituye un proceso de innegable desarrollo y magnitud en las sociedades actuales, adquiriendo centralidad en la mayor parte de las esferas de la vida contemporánea. Si bien en sus comienzos parecía un fenómeno a veces imperceptible, sus dimensiones actuales han logrado colocarlo como uno de los temas insoslayables de debate en distintos ámbitos: académico, político, económico, cultural.

En principio la idea de globalización ${ }^{17}$ sugiere totalidad, un proceso que envuelve

${ }^{16}$ Adherimos al concepto de mundialización de Revaro ORTIZ y el uso del término en este trabajo se ubica en ese registro.

17 ORTIZ, Renat0, ob.cit. pág.9 
todo a tal punto que las particularidades o especificidades se desdibujan ante un fenómeno que las supera, sin embargo, no desaparecen, conviven en el nuevo proceso. En todo caso, como bien se señala, se establecen entre las distintas "visiones del mundo" que puedan existir diferentes jerarquías.

Las pautas de consumo tienen la posibilidad de ser modificadas ante la circulación ilimitada de productos internacionales; las opciones de producción y distribución cultural e industrial se diversificaron a escala mundial y se imponen; la noción de espacio, tiempo y territorio se redefinen con la incorporación de nuevas tecnologías de la información y de la comunicación; la idea de Nación como supuesto de cohesión social pierde fuerza; la soberanía de los Estados nacionales es cuestionada; la institucionalidad política existente resulta insuficiente para responder a las nuevas demandas. Ahora bien ¿cuál es el alcance de todas estas manifestaciones de mundialización cultural? ¿hasta qué punto determinan las relaciones sociales en una comunidad política nacional?.

Nuestro interés es discutir las implicancias de este proceso en la idea de ciudadanía. Por tanto nuestro eje de reflexión seráel sentido y significado de las acciones de los sujetos sociales en una comunidad política. Se trata de un registro que se ubica en el plano de los valores y principios inherentes a la vida social y que si bien trasciende la materialidad de los bienes en sí mismos, trata de explicar cómo esos bienes al adquirir significado en la comunidad política constituyen bienes sociales.

La hipótesis que sustenta nuestra argumentación es que la mundialización es un proceso que efectivamente condiciona la vida social pero no necesariamente la determina. Es la comunidad política la que otorga significados comunes a los bienes sociales, es decir a aquellos que son portadores de valor y de sentido y que por tanto circulan, se distribuyen y se intercambian. En definitiva, el proceso de mundialización no presenta necesariamente un desenvolvimiento lineal ni tampoco determinante, sino que por el contrario, dada su complejidad, puede ser interferido por aquellos valores que asignan la pertenencia a una comunidad política y adquirir distintos matices y envergadura.

La sociedad humana es una comunidad distributiva ${ }^{18}$. Los hombres y mujeres se asocian a fin de compartir, dividir e intercambiar. La idea de justicia distributiva está asociada con el ser y el hacer, como así también con el tener, con la producción, con el consumo, con la identidad y el status, con el país, el capital o las posesiones personales. Las particularidades de la historia, de la cultura y de la pertenencia a un grupo otorgan sentido y significado a las acciones. Los bienes tienen significados compartidos porque

\footnotetext{
${ }^{18}$ Nuestra argumentación se basa en la obra de Michael WALZER, Las esferas de la justicia. Una defensa del
} pluralismo y la igualdad, Fondo de Cultura Económica, México, 1983. 
tanto su concepción como su creación son procesos sociales. Por esta misma razón los bienes tienen distintas significaciones en distintas sociedades.Todos los bienes que tienen valor distributivo son bienes sociales.

Los individuos asumen identidades concretas por la manera en que conciben y crean los bienes sociales. No existe por ello un solo conjunto de bienes básicos o primarios extensibible a todos los mundos morales y materiales. Es la carga de significaciones de los bienes lo que determina su movimiento. Los criterios y procedimientos distributivos son intrínsecos al bien social, no al bien despojado de significados. Los significados sociales se construyen históricamente al igual que las distribuciones, de allísu carácter dinámico y cambiante.

Por otra parte es en la comunidad política donde los bienes adquieren significados comunes. Es esta comunidad, señala Walzer, el entorno adecuado para demarcar significados y esferas distributivas. El lenguaje, la historia, la cultura, se unen para producir una conciencia colectiva. En la esfera política se establecen vínculos y se construyen interpretaciones compartidas entre los ciudadanos acerca del valor de la diversidad cultural y la autonomía local.

Los ciudadanos no sólo acceden a bienes que responden a sus necesidades sino que también tienen ideas acerca de los bienes que necesitan, les asignan prioridades, grados de necesidad y tales grados y prioridades se definen en uso de su autonomía para decidir y en razón de su naturaleza humana, de su historia y de su cultura.

Cuando hablamos de bienes sociales nos referimos ${ }^{19}$ a valores instalados en la comunidad política como pueden ser: el bienestar social, la justicia, la seguridad, la provisión, la libertad, la igualdad. También pueden constituirse otros bienes sociales como la riqueza, el poder, el honor, el reconocimiento, etc.

La pertenencia, constituye el bien primario en toda comunidad humana. El tener o no pertenencia estructura todas las opciones distributivas de bienes sociales. Los hombres y mujeres sin pertenencia son vulnerables y están desprotegidos, aislados de aquellos valores que otorgan sentido y significados. Este bien social es constituido por la propia comunidad.

Laciudadanía otorgapertenenciay a la vez opciones quese definen en la arenapolítica mediantelas decisiones colectivas. Los extraños, quienes no tienen pertenencia a una comunidad, "son como nosotros pero no son uno de nosotros", advierte Walzer. Esto es, no tienen la opciones de ciudadanía, sesitúan en un espacio de incertidumbre. Lapregunta que surgeen estalíneade

19 Siguiendo a WALZER, ob.cit. 
reflexión es jla llamada sociedad global tiene legitimidad para construir bienes sociales? 0 dicho de otro modo jla mundialización podrá definir un modelo cívico que garantice la cohesión social y la convivencia política democrática?.

\section{Las Tensiones en la CiUdadanía: Entre la Universalidad y la Particularidad}

La ciudadanía de naturaleza universal surge de la matriz de Seguridad Social. El Estado, a través de las políticas públicas de acción centralizada y unificada, garantiza a todos los ciudadanos un mínimo vital de bienes y servicios. La política económica y la política social se articulan como partes indisociables de una mismaestrategia de desarrollo. El Estado es el principal financiador y administrador del Sistema. Los beneficios universales son otorgados con el status de derechos.

Este formato de ciudadanía ha predominado durante la vigencia de modelos de Estado intervencionista y fue la mediación más importante en la reconstitución de la sociedad para garantizar la integración social. El objetivo central fue alcanzar la igualdad social aún a costa de generar una cultura política homogénea. La universalidad era por tanto un presupuesto inherente a la existencia misma de la ciudadanía.

Daniel Bell ${ }^{20}$ al mostrar las contradicciones culturales del capitalismo explica las razones por las cuales el Estado de bienestar, con tal de alcanzar la igualdad de oportunidades en los ámbitos más relevantes de la sociedad -salud, educación, alimentación, etc.- genera paralelamente una modalidad de cultura pública política que promueve la formación de identidades de grupo, de identidades colectivas. La búsqueda de la igualdad social incentiva una cultura corporativa homogénea.

El Estado de Bienestar promueve de esta manera una "cultura de la justicia corporativa de grupo" a partir del reconocimiento, en términos de política social, de las formas específicas de discriminación y perjuicio contra los diferentes grupos. Esta cultura corporativa genera una "identidad corporativa" en relación a formas de identidad de grupo reconocidas, sancionadas y legitimadas oficialmente por el Estado y sus instituciones. La formación de "identidades corporativas" de grupo del Estado de Bienestar es, en buena medida, una consecuencia de la política de redistribución especíicamente ligada a la lógica de ese Estado de Bienestar. En este sentido, podríamos pensar que una vez garantizados los derechos sociales básicos durante la vigencia de modelos de estado

${ }^{20}$ Bell, Daniel, Las contradicciones culturales del capitalismo, Alianza Universidad, Madrid, 1976. 
intervencionistas, se comienza a reclamar la aceptación y respeto de la diferencia en el plano cultural a fin de recuperar identidades que habían sido desdibujadas.

Algunos estudios empíricos ${ }^{21}$ realizados en América Latina en relación al problema de género en la ciudadanía permiten reafirmar esta hipótesis, al constatar que en aquellos sectores sociales donde los derechos sociales básicos están garantizados, la concepción acerca del género es diferente que en aquellos donde aún esas necesidades no han sido satisfechas. En los primeros, las mujeres se reconocen como sujetos de derecho autónomos y luchan por esta reivindicación, mientras que en los segundos la mujer actúa como intermediaria entre el Estado y la familia, utilizando sus roles domésticos para garantizar lasatisfacción de necesidades básicas.

La "política del reconocimiento" y la "política de la identidad" han constituido temas centrales de debate en las últimas décadas" ${ }^{22}$, tanto en la filosofía política como en la sociología, como consecuencia de las luchas de los nuevos movimientos sociales por el reconocimiento de derechos con el objetivo de situar el problema del multiculturalismo, las minorías y la diferencia en el campo de referencia de la ciudadanía. Así, la identidad y la diferencia cobran fuerza a la hora de designar las peculiaridades de la nueva política, así como también las "luchas por el reconocimiento" o la "distribución del reconocimiento" adquieren relevancia. En definitiva, en este nuevo escenario se ponen en cuestión todas las exigencias relativas a la igualdad social.

El problema de fondo que se discute es la capacidad de tolerancia que tienen tanto la "universalidad" como la "igualdad" para reconocery otorgar valor a la diferencia. Ya se trate de diferentes culturas o bien diferencias de raza, sexo, religión, etc. No sólo se pretende que puedan sobrevivir y se declamen tales afirmaciones, sino que se reconozca su igual valor. Taylor, señalaba que se trata de saber si la supervivencia cultural sería reconocida como meta legítima, es decir si los objetivos colectivos se tolerarían como consideraciones legítimas en la revisión judicial o para otros propósitos de la política ${ }^{23}$. Así como todos los ciudadanos deben tener derechos civiles y políticos, sin importar su raza y cultura, también deben disfrutar de la posibilidad de que su cultura tradicional tenga un valor. Sin embargo, esta afirmación que pareciera fluir de manera lógica de las

${ }^{21}$ Ver Provoste Fernández, Patricia y Valdés Barrientos, Alejandra "Democratización de la gestión municipal y ciudadania de las mujeres: sistematización de experiencias innovadoras", Biblioteca de ideas, Colección de Papers, Instituto Internacional de Gobernabilidad, PNud, abril 2001, pág. 20.

22 SEYLA BenHaBiB, afirma que en las democracias capitalistas occidentales estos conceptos surgen originariamente a finales de los años 70 y comienzos de los ochenta, en Diversitat cultural, igualtat democratica, Tandem argumentes, Valencia, 2000, pág.18.

${ }^{23}$ Taylor, Charles, El multiculturalismo y "la política del reconocimiento", FCE, México, 1993, pág.94 
normas que regulan los postulados de la igualdad, advierte el autor, en realidad es desafiada por "la ceguera a la diferencia" que ocupa en esa lógica un lugar central.

Un enfoque crítico ${ }^{24}$ a la política de reconocimiento, permite advertir que todo reconocimiento supone una necesidad humana universal de aceptación incondicional. La formación de laidentidad de una persona, como también su reconocimiento están estrechamente vinculados a la idea de "reconocimiento social positivo" que implica aceptación y respeto por parte de sus vínculos más próximos y también de la sociedad en general. Los seres humanos necesitan de manera permanente reafirmar su sentido de pertenencia a la sociedad y también al universo como totalidad. Por tanto la diferencia adquiere sentido y valor cuando logra inscribirse en los parámetros universales de una comunidad.

Nuevamente la disputa entre liberales y comunitaristas se restablece. El principio de universalidad y status legal de los derechos individuales son baluartes heredados del liberalismo. Desde esta matriz de pensamiento los derechos humanos, que garantizan a los ciudadanos la vida y la libertad privada necesarios para la realización de sus planes de vida, fundamentan por sí mismos un dominio legítimo de la leyes. Esto es, los derechos humanos establecen los límites que deben impedir a la soberana voluntad de un pueblo o comunidad la intrusión en la inviolable esfera de las libertades privadas de los sujetos.

Los comunitaristas contribuyen con la idea de comunidad política y participación. Predomina la idea de comunidad, de bien común, por sobre los derechos individuales. Desde esta perspectiva, los derechos humanos deben su legitimidad a la auto comprensión ética y la autodeterminación soberana de una comunidad política. Conceden a la comunidad la primacía sobre el individuo, desconociendo la separación entre ética y derecho. Predominan los deberes ante la comunidad antes que los derechos de los ciudadanos. No reconoce los derechos subjetivos, sino solamente derechos otorgados a individuos en razón de su vinculación a una comunidad. En este pensamiento el particularismo no acepta el universalismo.

El carácter universal de los derechos humanos también es puesto es cuestión, no obstante representan el único fundamento reconocido legítimamente por la comunidad política internacional, aceptado por la mayor parte de los Estados en la Declaración de los Derechos Humanos de las Naciones Unidad. Sin embargo, tanto su validez universal como el contenido y rango de derechos humanos son discutidos ${ }^{25}$.

Es importante aclarar, que los conceptos "universal" y "particular no siempre han

${ }^{24}$ ROCKEFELLER, STEven, en El multiculturalismo..., ob.cit. pág. 136.

${ }_{25}$ Para ampliar este punto, remito a Habermas, Jurgen La constelación posnacional, Paidós, Buenos Aires, 2000, pág. 147. 
sido utilizados en el mismo sentido en ambos debates. Pero también hay que destacar que la interacción producida como producto de ese debate ha logrado una producción política considerable $^{26}$.

En este debate, Habermas sostiene que las posiciones particularistas, de referencias culturales diferenciadas, orientan el debate en una dirección equivocada. Los derechos subjetivos cumplen la función de "estuche protector para la conducción de la vida privada de las personas"en un doble sentido: protegen la posibilidad de desarrollar un proyecto ético vital y, por otro lado, garantizan una orientación libre de acuerdo a sus propias preferencias, sin condicionamientos morales.

Ahora bien, uno de los supuestos que demanda la nueva configuración de las sociedades globalizadas es justamente redefinir el "nosotros" permitiendo que el "otro" pueda ser considerado uno de "nosotros". Es decir se cuestiona el "nosotros" pero también se transforma la noción del "otro"27. En el campo de la ciudadanía el debate en esta dirección ha cobrado centralidad y la literatura desde distintos enfoques busca orientar alternativas. Los diferentes enfoques en torno al problema, que exceden las posibilidades de desarrollo en este trabajo, oscilan desde cuestionar la ciudadanía como marco análitico adecuado para entender los cambios de la sociedad actual, hasta proclamar tantos modelos de ciudadanía como grupos diferenciados existen en la sociedad. En las páginas que siguen, presentamos el debate y adoptamos una posición en este sentido.

\section{CIUdAdANÍA Universal e InClusión SOCIAL}

No se pueden negar hoy las pertenencias ni las identidades particulares para acceder a un punto de vista donde reine el individuo abstracto y universal. El ciudadano democrático sólo puede ser concebido en el contexto de un nuevo tipo de articulación entre lo universal y lo particular de acuerdo con una modalidad de universalismo que integre las diversidades horizontalmente. La idea es indicar que lo universal se inscribe en el corazón de lo particular y en el respeto a las diferencias ${ }^{28}$.

La democracia en la modernidad supone el reconocimiento de la dimensión antagónica de lo político. La política consiste siempre en "domesticar la hostilidad"y en tratar de neutralizar el antagonismo potencial que emerge en toda construcción de

\footnotetext{
${ }^{26}$ Laclau, ERnesto, Emancipación y diferencia, Ed. Ariel,Bs.As. 1996, pág.88.

${ }^{27}$ OrTiz, Renato, ob. Cit. Pág. 219.

${ }^{28}$ En este punto nuestra argumentación se sostiene en la propuesta de CHANTAL, MoufFe de ciudadanía democrática plural. Ob.cit.
} 
identidades colectivas. La construcción de un "nosotros" distinto, genera necesariamente un contexto de diversidad y de conflicto. Lo importante es que la democracia permita que ese conflicto se exprese, pero paralelamente para sostenerse deberá construir ciertas formas de consenso. Aunque el consenso, advierte Mouffe, siempre se basa en actos de exclusión.

En las luchas por el reconocimiento, por las diferencias, se encuentra presente una articulación compleja entre reivindicaciones que dependen de la igualdad y reivindicaciones que pertenecen a la esfera de la libertad. La manera de canalizar estas nuevas expresiones en el espacio político es a partir de lo que se ha denominado "democracia plural y radical", desde donde se articula un modelo de ciudadanía democrática plural. Desde esta noción, se trata de definir nuevos usos y nuevas significaciones para la idea de libertad e igualdad.

Su propuesta está centrada en la idea de que una política democrática debe multiplicar los espacios en los que las relaciones de poder estarán abiertas a la contestación democrática. No se trata de erradicar el poder ni tampoco concentrarlo. Se requiere una hegemonía de valores que se puedan viabilizar en múltiples prácticas democráticas, institucionalizándolas en relaciones sociales variadas, de modo que pueda generarse una multiplicidad de posiciones subjetivas desde una matriz democrática.

Este enfoque pone énfasis en una idea de ciudadanía que permite la constitución de un polo de identificación que agrupará los diferentes movimientos que luchan por la ampliación de derechos, en un conjunto de relaciones sociales diversas. En este proceso político tanto el conflicto como la división siempre van a estar presentes. Existirán consensos, pero siempre van a ser provisionales.

La ciudadanía es concebida como identidad política que se crea a partir de la identificación con la comunidad pública, con la respública. En esta idea es posible identificar algunos supuestos que permiten pensar en un nuevo concepto de ciudadanía. La noción de ciudadanía como un tipo de identidad política, implica una forma de identificación para Mouffe y no simplemente un status legal. No pone todo el énfasis en los derechos, sino que parte de ese reconocimiento y avanza hacia la consideración de la ciudadanía como identidad política.

La identidad política común involucra a un conjunto de personas que pueden comprometerse individualmente con objetivos y emprendimientos personales diferentes y mantener distintas concepciones del bien, pero para el logro de esos objetivos y de las acciones que proponen, aceptan el sometimiento a reglas que prescribe la comunidad política pública. Lo que mantiene unidas a las personas es una comunidad pública, el reconocimiento común de un conjunto de valores ético-políticos. En este caso la 
ciudadanía no es sólo una identidad entre otras ni la identidad que domina o se impone a las otras, aclara la autora. Es un principio de articulación que afecta a las diferentes posiciones subjetivas de los agentes sociales, aunque reconociendo una pluralidad de lealtades específicas y el respeto a la libertad individual.

En una democracia de este tipo los grupos que luchan por la extensión de sus espacios y de sus derechos desconocen que tienen un interés común y que al elegir sus acciones deberían adherirse a ciertas reglas, a aquéllas que permitan construir una identidad política donde sus proyectos puedan realizarse como ciudadanos. Esas reglas no imponen, ni prohíben, ni garantizan acciones a los miembros de una comunidad. № dicen lo que deben o no deben hacer porque se respeta la libertad individual. Pero la pertenencia del individuo a la comunidad y la identificación política con sus principios ético-políticos se manifiestan en su aceptación. La comunidad política proporciona la "gramática de la conducta del ciudadano".

Se trata de una concepción de ciudadanía que apunta a la construcción de un "nosotros" a partir de una identificación común con una interpretación democrática radical de los principios de libertad e igualdad. Esa construcción de un "nosotros"se establece sobre la base de una cadena de equivalencias entre sus demandas a fin de articularlas con los principios democráticos de libertad e igualdad. No se pretende entonces, una mera alianza de intereses particulares sino de modificar realmente la identidad misma de estas fuerzas.

Este cambio no implica un suave proceso de inclusión o de reconocimiento de derechos como pretendía el liberalismo. En esta extensión hay conflictos, antagonismos propios de la lucha por la extensión de la democracia. El problema del enfoque liberal, según Mouffe, es que ignora los límites que impone la extensión del pluralismo debido a que algunos de los derechos existentes se han constituído mediante la exclusión 0 subordinación de los derechos de otros sujetos sociales. Para fundar una nueva ciudadanía y reconocer nuevos derechos es preciso primero "deconstruir esas identidades".

Hacen falta nuevas identidades que adhieran a una identidad política común como ciudadanos. Esto es, que haya una identificación colectiva con ciertos principios de manera que se tomen en cuenta las diferentes relaciones sociales y las distintas posiciones subjetivas en que son pertinentes: género, raza, etnia, orientación sexual, etc. Se requiere concebir al agente social no como sujeto unitario en sí mismo, sino como portador de identidad e identificación. La noción de comunidad política no puede ser reducida a un referente empírico, sino como superficie discursiva.

La matriz universalista, abstracta de particularidad y diferencia, no puede ser 
sostenida porque no sólo constituye un obtáculo a la extensión de ciudadanía, sino que la deslegitima en sus fundamentos constitutivos y su sentido político y social.

Desde esta perspectiva se reformula la relación público/privado. En relación al género, por ejemplo, el dominio público de la ciudadanía moderna se basó en la negación de la participación de las mujeres. Esta exclusión fue considerada indispensable para sostener la generalidad y la universalidad de la esfera pública. En este registro, la distinción público/privado primordial para la afirmación de la libertad individual, determinó la identificación de lo privado con lo doméstico y subordinó a las mujeres.

En una sociedad, toda situación se dirime ante una disputa entre lo público y lo privado. Esto es, hay aspectos de las acciones privadas que dependen en su realización de ciertas condiciones de la esfera pública. Los deseos, las decisiones, las elecciones, son privadas, porque expresan la voluntad y responsabilidad de cada individuo, pero sus realizaciones son posibles en la esfera pública.

La idea de universalidad es desafiada desde esta propuestapor la identificación con los principiosético-políticos de lademocracia moderna. Por tanto, puede haber tantas formas de ciudadanía como interpretaciones de esos principios puedan existir. La ciudadanía puede, entonces, contribuir a la extensión de los principios de libertad e igualdady por tanto garantizar un modelo inclusivo en el nuevo mapa del mundo. Pero también, señala Mouffe, la combinación del ideal de derechos ypluralismo y las ideas deinspiración públicay preocupación ético-política podrían restaurar la dignidad de lo político.

Recebido em julho de 2004. 